\title{
Teachers' Views on the Role of Science Practical Activities in the Teaching of Science in Ghanaian Senior Secondary Schools
}

\author{
Ghartey-Ampiah, J. \\ Institute of Education, University of Cape Coast \\ Tufuor, J. K. \\ Department of Science Education, University of Cape Coast \\ and \\ Gadzekpo, V. P. Y. \\ Department of Chemistry, University of Cape Coast
}

\begin{abstract}
Ghana, like many other countries, has a strong tradition of doing practical work in senior secondary school science. In line with this tradition, the Senior Secondary School (SSS) science syllabuses issued by Curriculum Research and Development Division, and the West African Examination Council emphasise attainment of scientific knowledge, development of laboratory skills, and attitudes. This study surveyed the views of 50 science teachers' in 10 SSS in the Central Region of Ghana on the role science practical activities play in the teaching and learning of science using a questionnaire. Teachers' views on the role of science practical activities were mainly that of using them to support the teaching of scientific knowledge, and to some extent the development of attitudinal and laboratory skills. There was little emphasis on the use of science practical work to develop students' cognitive skills.
\end{abstract}

\section{Introduction}

The literature on science practical work shows that laboratories for the conduct of scientific research have existed at least since the seventeenth century. However, according to Jenkins (1998), the use of the science teaching laboratory, designed and equipped to teach science to students, is essentially a nineteenth-century phenomenon. Since the beginning of the $20^{\text {th }}$ Century, there has been continuous increase in the supply of facilities and equipment suitable for practical science teaching in schools. This awareness of the importance of science became more prominent after the Russians launched their first satellite (Sputnik) in 1957. From that time, new American and English curricula spread to different parts of the world including Africa. By the late 1950s, some initiatives were taken which led to the large-scale curriculum reform movements in the 1960s in England and Wales. This was first funded by the Nuffield Foundation, and later by the Schools Council, set up in 1964 (Jenkins, 1998). In the 1960s, another cycle of science curriculum development began in England and Wales and concentration on laboratory work increased. According to Jenkins, in the Nuffield Projects, pupils were "as far as possible, to engage in investigative activities and, thereby gain vicarious experience of scientific discovery" (p. 46). This project lent important support to the idea that had already been mooted that all science teaching should be laboratory-based. 
In Africa prior to the 1950 s, the textbook was the curriculum for science and hence what passed as the teaching of science was nothing more than information-giving by teachers and memorisation of the information by students (Collison \& Aidoo-Taylor, 1990). The theoretical approach to teaching science was further encouraged by the emphasis it received in public examinations (Ajeyalemi, 1990). However, according to Collison and AidooTaylor (1990), since the 1980s, attempts have been made in Africa as a whole, and Ghana in particular to use practical activities with the aim of providing opportunities for students to solve problems, learn enquiry processes and develop decision-making skills. The West African Examinations Council (WAEC) from 1998 to 2002 for example, emphasizes the acquisition of practical skills in biology, physics and chemistry as follows:

Biology

(a) acquisition of adequate laboratory and field skills in order to carry out and evaluate experiments and projects in biology;

(b) acquisition of the necessary scientific skills for example, observing, classifying and interpreting biological data.

Physics

(a) carry out experimental procedures using apparatus;

(b) develop abilities, attitudes and skills that encourage efficient and safe practice;

(c) make and record observations, measurements and estimates with due regard to precision, accuracy and units.

Chemistry

(a) enable students to develop laboratory skills, including an awareness of hazards in the laboratory and the safety measures required to prevent them;

(b) enable students to appreciate the scientific method which involves experimentation, accurate observation, recording, deduction and interpretation of scientific data

Hence the examination in each science subject (physics, chemistry and biology) consists of a theory paper and a practical paper. The practical paper is based on the content of the particular science subject. This according to Collison and Aidoo-Taylor (1990) is "intended to determine how well the candidates understand the nature of scientific investigation and the use of apparatus in a controlled experiment to determine an answer to a question" (p.17). According to Woolnough (1998) one way of looking at science practical activities is to categorize them broadly into those related to developing practical skills and attitudes; and those related to discovering or elucidating theory. The latter makes use of structured experiments linked to theory. Those who argue in favour of practical activities are however, divided on its aims and how it should be organized so as to help students. They differ greatly in what skills are important and how they can be achieved. Some rank the aims related to practical skills more highly than those related to developing theory, and vice 
versa. In two major research exercises in the 1960s and 1970s reported by Millar (1998), teachers were asked to rank in order of importance lists of possible aims of practical work. Two of the main groups of aims ranked very high by teachers were those, which concern the role of practical work in supporting the teaching of scientific knowledge, and in teaching the processes of scientific enquiry. As noted by Millar (1998), "an investigative or enquiry approach encourages children to be more independent and self-reliant, to think of themselves as able to pose their own questions about the physical world and to find answers to them through their own efforts" (p. 17). It seems that much of what is said about practical work stems from this view about the use of the enquiry approach in the teaching of science. In reality, Millar (1998) felt that what practical work does is simply to reproduce a phenomenon, which has already been established (Millar, 1998). However, as noted by Hacking (1983), repeating what has been done serves two purposes for the teaching and learning of science. The first is that it shows a phenomenon can be reliably reproduced so that students could learn at first hand from the phenomenon instead of it being described to them, and they trying to visualise it. Secondly, since phenomenon is not easy to reproduce, the successful outcome of a practical activity is evidence that students have carried out the activity correctly, and with sufficient care and skill. Students are able to learn new ideas by being shown examples of them, rather than being given formal definitions, or other verbal accounts. As pointed out by Millar (1998), "when we get pupils to investigate the relationship between force and acceleration for a trolley, for instance, we are showing what the scientific ideas of 'force' and of 'acceleration' mean, by giving concrete examples of them" (p. 29). Essentially then, according to Millar (1998) whatever teachers may say about why they conduct practical work, the real purposes of practical work done in schools is to try to

encourage students to make links between things they can see and handle, and ideas they may entertain which might account for their observation ... Practical work that is intended to support the teaching and learning of scientific knowledge has to be understood, and judged, as a communicating strategy, as a means of augmenting what can be achieved by word, picture and gesture (p. 29, 30).

Science practical work may therefore involve illustrations of a phenomenon, providing experiences or getting a feel for phenomenon by students, exercises or routines for students to follow, developing a particular skill, or becoming used to a piece of equipment or instrument.

Other surveys conducted over the past thirty years into reasons why teachers do practical work and the type of practical activities they do are reported by Woolnough (1998). According to him, teachers ranked those aims related to developing practical skills and attitudes most highly and those related to discovering or elucidating theory much lower. Yet Woolnough has observed that the type of practical work teachers consistently say that they do most frequently are structured experiments linked to theory (practical work to elucidate theory). Given the emphasis science syllabuses place on practical work in Ghana it is of interest to find out Ghanaian science teachers views on the role science practical activities play in the teaching of learning of science. 


\section{Purpose of the study}

In Ghana, like many other countries, there is a strong tradition of doing practical work in school science. This is because practical work is emphasised by the CRDD and WAEC science syllabuses and are examined externally by the WAEC. The key aims of the syllabuses are essentially the attainment of scientific knowledge, and the development of practical skills and attitudes.

It is widely acknowledged that for many students, scientific concepts may be abstract and difficult to grasp, hence teachers use different methods including practical activities to improve student understanding of such concepts. Practical work is considered to be effective as it allows students to change the abstract to the concrete, thus helping in the internalisation and understanding of concepts (Arce and Betancourt, 1997). There is however, a growing body of evidence indicating that despite this emphasis on practical work, much school science teaching is unsuccessful in giving students an understanding of the ideas of science and development of some scientific skills (Clarkson and Wright, 1992; Hodson, 1992). It is in the context of these findings that this study explored science teachers' views on the role science practical work plays in the teaching and learning of science in the Ghanaian context.

\section{Subjects}

The Central Region had 49 SSS, with 18 of them offering all three elective science subjects during the time of this study. In the 10 schools, where this study was conducted, all elective science teachers at post at the time of the study formed the subjects of the study. There were 60 science teachers available to respond to the questionnaires, out of which 50 questionnaires were completed and returned.

\section{Instrument}

The instrument used for the study was "Questionnaire on the Role of Science Practical Work". The questionnaire was designed after small-scale investigations of science practical lessons in some SSS. Discussions with science teachers and those acquainted with practical work at the SSS level also informed the design of the instrument. The questionnaire was validated by the researchers and other science educators at the University of Cape Coast. The draft questionnaire was pre-tested in two schools in the Central Region of Ghana.

\section{Procedure}

The questionnaire was administered to science teachers with the assistance of the Heads of Science Departments in the various schools. As much as possible, all questionnaires administered to science teachers were collected by the third day. Non responses were followed up thrice before attempts to retrieve the completed questionnaires were abandoned. This procedure resulted in a return rate of $83 \%$. 


\section{Results and Discussion}

The spectrum of views expressed by teachers on the role of practical work can be categorized into three. They are as follows: Science practical activities

(a) help students understand the concepts or theoretical aspects better and this aids teaching and appreciation of science;

(b) enable students to develop practical skills, collect, record and analyse data;

(c) enable students to verify facts and principles that are taught in class.

These views expressed by science teachers are in agreement with the aims of practical work contained in CRDD and WAEC science syllabuses.

However, when science teachers were asked to rank nine reasons for organising practical work, Table 1 shows that they ranked low, reasons, which were related to helping students to find facts and arriving at new principles, seeking for problems, and finding ways to solve them.

Table 1 Teachers' ranking of reasons for organising science practical activities

\begin{tabular}{|l|l|}
\hline Reasons & Rank \\
\hline To use science practical to clarify theory & High \\
\hline To verify facts and principles already taught & Medium \\
\hline To arouse and maintain interest in science & Medium \\
\hline For students to develop specific manipulative skills & Medium \\
\hline To encourage accurate observation & Medium \\
\hline For finding facts and arriving at new principles & Low \\
\hline To satisfy the science syllabus and WAEC examination requirements & Low \\
\hline To enable students pass their final examination & Low \\
\hline To practice looking for problems and seeking ways to solve them & Low \\
\hline
\end{tabular}

This confirms similar findings by other researchers elsewhere (Kerr, Thompson, Beatty \& Woolnough as cited in Woolnough, 1998). Teachers also ranked low, reasons related to satisfying WAEC examination requirements, and helping students pass science practical examinations. These rankings were in agreement with views expressed by teachers in open-ended questions on the same issue. Reasons related to using practical work to clarify theory taught in class were ranked high by teachers, whilst those related to verification of facts and acquisition of manipulative skills were ranked medium. It must be noted that reasons for organizing practical work ranked high or medium by teachers are in line with the objectives of the CRDD and WAEC science syllabuses. Table 1 , therefore portrays teachers' views on the role of science practical work as essentially that of helping students understand theory or content taught in science classes. This is supported by the results shown in Table 2. The table shows that generally, teachers organised practical activities to verify theory more often than not $(96.0 \%)$. The majority of teachers $(80.0 \%)$ with a mean of 
3.04 , indicated they always $(30.0 \%)$ or very often $(50.0 \%)$ conducted practical activities to achieve such a purpose.

The mean scores also indicate that teachers more often tended to conduct practical activities with the intention of developing laboratory skills (2.82) followed by developing scientific attitudes (2.58).

This means that about half of the science practical activities conducted by teachers were geared towards the development of scientific attitudes. The table however, shows a very low mean of 1.42 with $60.0 \%$ of the teachers indicting that they rarely or never allowed students to design and perform their own experiments. This however, is one of the objectives for conducting science practical activities as stated in the science syllabuses.

Table 2 Mean scores and percentage responses in each category for each item $(\mathrm{N}=50)$

\begin{tabular}{|c|c|c|c|c|c|}
\hline Type of science practical & 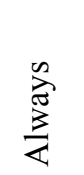 & $\begin{array}{l}\stackrel{0}{0} \\
\stackrel{0}{0} \\
\stackrel{0}{0} \\
>\end{array}$ & $\stackrel{\Xi}{0}$ & 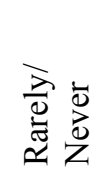 & $\sum_{\Sigma}^{\tilde{\Sigma}}$ \\
\hline Practical to verify theory already taught in class & 30.0 & 50.0 & 16.0 & 4.0 & 3.04 \\
\hline $\begin{array}{l}\text { Practical designed to help students develop } \\
\text { laboratory skills }\end{array}$ & 20.0 & 44.0 & 32.0 & 4.0 & 2.82 \\
\hline $\begin{array}{l}\text { Practical designed to help students develop } \\
\text { scientific attitudes }\end{array}$ & 12.0 & 42.0 & 36.0 & 10.0 & 2.58 \\
\hline $\begin{array}{l}\text { Project work designed by students based on a } \\
\text { problem of their choice }\end{array}$ & 0 & 2.0 & 38.0 & 60.0 & 1.42 \\
\hline
\end{tabular}

The lack of emphasis on the design and performance of experiments by students means that students have very little opportunity to identify their own problems, play a role in the design of appropriate experiments, as well as collect and interpret data themselves. Therefore, if students rarely pursue such activities, it would be difficult for them to develop cognitive skills associated with problem solving (Arce and Betancourt, 1997). Studies by Hannon (1994) and Arce and Betancourt (1997) have shown that when students are allowed to design their own experiments, they become motivated, curious, enthusiastic and confident. According to them, students find practical work challenging and rewarding as a result of this. Also Hodson (1990) acknowledges the fact that if students are allowed to pursue their own investigations in their own way through practical work, it can result in higher motivational power. It is therefore disappointing that majority of teachers stated that they did not allow their students to design and try experiments on their own. In assigning reasons for this, some teachers mentioned lack of equipment, large class sizes, and syllabuses overloaded with content. Others stated that their aim of conducting practical work was to cover the activities suggested in the WAEC syllabuses and that there was no time and room for individual adventurism. Apart from these, the problem of time constraint was the most cited reason by teachers for not 
allowing individual students the liberty to design and perform their own experiments. According to those who gave this reason, there was so much work to do in completing the science syllabuses that students would not have the time to design and carry out their own experiments. Some teachers also felt that it would not serve any purpose for students to design their own experiments and carry them out, and pointed to the final WAEC science practical examination, which they said did not ask candidates to design their own experiments. Others thought it was not feasible for each of the over 50 science students in their class to design experiments and carry them out since as one of them put it "there will be confusion in the laboratory". Most teachers pointed out that designing and performing experiments by students could only be done if there were fewer students as teachers need to supervise them. Even the $38.0 \%$ of teachers who indicated that they allowed their students to carry out individual investigations stated that students did so for science exhibitions during speech and prize-giving days in their schools. Only two teachers gave reasons related to encouraging students to be innovative and creative. Teachers therefore did not emphasise some of the objectives for conducting science practical activities as contained in the WAEC and CRDD syllabuses

Teachers were also asked to rank 10 practical skills students could develop during science practical work in order of importance. Three out of the 10 skills were related to development of attitudes, two directly related to laboratory skills, and the rest to cognitive skills. Table 3 presents the results of teachers' ranking. It can be seen from the table that teachers ranked high or medium all the attitudinal and laboratory skills but ranked low, cognitive skills.

Table 3 Teachers' ranking of practical skills in terms of importance

\begin{tabular}{ll}
\hline Practical skills & Rank \\
\hline Observing & High \\
Manipulative & Medium \\
Initiative & Medium/High \\
Objectivity & Medium \\
Integrity & Medium \\
Problem formulation & Medium/High \\
Experimental design & Medium/Low \\
Predicting & Low \\
Drawing conclusions & Low \\
Hypothesizing & Low \\
\hline
\end{tabular}

This means that general scientific skills such as predicting, drawing conclusions and hypothesizing, which are related to the development of cognitive skills but which are not necessarily laboratory based were all ranked low. This is not surprising as the final WAEC practical examination has very little if anything at all to do with the development of the general scientific skills listed. However, general scientific skills which teachers ranked low (predicting, 
drawing conclusions and hypothesizing) are rather those skills that can lead to the development of understanding of the concepts and procedures involved in science which students need to acquire (Arce and Betancourt, 1997).

Barton (1998) has observed that "too often the time and effort expended in collecting and processing the data tend to squeeze out activities related to analysis and interpretation of data" (p. 238). This seems to be the case, judging from teachers' responses. However, without analysis and interpretation, and drawing of conclusions, it would be difficult to link students' practical experiences with abstract concepts. However, helping students to make this link is an important process, and one, which should form one of the core activities during science practical periods. The study however, shows that science teachers saw this as less important compared to other skills.

\section{Conclusion}

Evidence from the study suggests that teachers' views of the role of science practical activities were dominated by the desire to help students understand theory and to a lesser extent, the development of laboratory and attitudinal skills. Teachers thus ranked the aims of practical work related to clarifying theory more highly than those related to developing practical skills. It seems this role of science practical work, has taken the centre stage in the teaching and learning of science, and has become the main reasons, though not exclusively, for conducting practical activities in schools. Ironically, Barton (1998) states that "many of the criticisms levelled against practical work focus on difficulties related to teaching 'theory' through practical work" (p. 238). In spite of the criticisms stated by Barton, it is contended that students' trying to find out information by themselves through practical work is a useful exercise, regardless of whether or not that knowledge is already known (Hacking, 1983). Practical skills such as manipulation of apparatus and observation even though ranked medium by teachers are not complete in themselves as they only constitute the first hand experience phase of science practical work. This should be followed by analysis and interpretation of the data collected, which were ranked low by teachers.

The findings of this study give support to the growing body of evidence that even though there is emphasis on practical work in the teaching and learning of science by the CRDD and WAEC science syllabuses, the conduct of science practical activities in the schools studied were more skewed towards the understanding of science content taught in the classroom than the development of scientific attitudes and the spectrum of scientific skills as envisaged by the science syllabuses (Clarkson and Wright, 1992; Hodson, 1992). Teachers' lack of emphasis on the development of cognitive skills may stem from the fact that these skills are not examined by WAEC. This tends to lend credence to the fact that teachers have the WAEC practical examination in mind when they organise science practical activities for students, even though they rated low reasons for conducting science practical activities related to satisfying WAEC practical examinations. 


\section{Recommendation}

It is important for science teachers to conduct practical activities in line with the objectives of the WAEC and CRDD syllabuses and for the WAEC to examine all aspects of the objectives for asking teachers to conduct practical activities in school. This will make science teachers play equal attention to the development of cognitive, attitudinal and laboratory skills when they organise science practical activities.

\section{References}

Arce, J., \& Betancourt, R. (1997). Student-designed experiments in scientific laboratory instruction. Journal of College Science Teaching, 114-118.

Ajeyalemi, D. (1990). Science and technology education in perspective. In D. Ajeyalemi (Ed.). Science and technology education in Africa: focus on seven sub-saharan countries (pp. 4-12). Lagos: University of Lagos.

Barton, R. (1998). IT in practical work. In J. Wellington (Ed.), Practical Work in School Science (pp 237-251). London: Routledge.

Clarkson, S.G. \& Wright, D.K. (1992). An appraisal practical work in science education. School Science Review, 74 (266), 39-42.

Collison, G.O., \& Aidoo-Taylor, N. (1990). Ghana. In D. Ajeyalemi (Ed.). Science and technology education in Africa: focus on seven sub-saharan countries (pp. 13-25). Lagos: University of Lagos.

Hacking, I. (1983). A critical look at practical work in school science. School Science Review, 71 (256), 33-40.

Hannon, M. (1994). The place of investigations in science education. Education in Science, 33-34.

Hodson, D. (1990). A critical look at practical work in school science. School Science Review, 70 (256), 33-40.

Hodson, D. (1992). Redefining and re-orientating practical work in school science. School Science Review, 73 (264), 65-78.

Jenkins, E. (1998). The schooling of laboratory science. In J. Wellington (Ed.), Practical work in school science, (pp 35-51). London: Routledge.

Millar, R. (1998). Rhetoric and reality: what practical work in science education is really for. In J. Wellington (Ed.), Practical Work in School Science (pp. 16-31). London: Routledge.

Woolnough, B. E. (1998). Authentic science in schools. In J. Wellington (Ed.) Practical work in school science, (pp109-125). London: Routledge. 